\title{
비화학양론적인 $\left(\mathrm{K}_{0.5} \mathrm{Na}_{0.5}\right)_{0.97}\left(\mathrm{Nb}_{0.96-\mathrm{x}} \mathrm{Ta}_{\mathrm{x}} \mathrm{Sb}_{0.04}\right) \mathrm{O}_{3}$ 세라믹스의 유전 및 압전특성
}

\author{
신상훈 ${ }^{1}$, 노정래 ${ }^{1}$, 류주현 ${ }^{1, a}$ \\ 1 세명대학교 전기공학과
}

\section{Piezoelectric and Dielectric Properties of Non-stochiometric $\left(\mathrm{K}_{0.5} \mathrm{Na}_{0.5}\right)_{0.97}\left(\mathrm{Nb}_{0.96-\mathrm{x}} \mathrm{Ta}_{\mathrm{x}} \mathrm{Sb}_{0.04}\right) \mathrm{O}_{3}$ Ceramics}

\author{
Sanghoon $\operatorname{Sin}^{1}$, Noh jung-rae ${ }^{1}$, and Juhyun Yoo,a \\ ${ }^{1}$ Department of Electrical Engineering, Semyung University, Jecheon 390-711, Korea
}

(Received July 5, 2012; Revised July 20, 2012; Accepted July 24, 2012)

\begin{abstract}
In this study non-stoichiometric $\left(\mathrm{K}_{0.5 \mathrm{Na}} \mathrm{Na}_{0.5}\right)_{0.97}\left(\mathrm{Nb}_{0.96}-\mathrm{xTa}_{\mathbf{x}} \mathrm{Sb}_{0.04}\right) \mathrm{O}_{3}$ ceramics were prepared by the conventional soild-state teaction method. The effect of $\mathrm{Ta}^{-}$-substitution on the dielectric and piezoelectric properties were investigated. $\mathrm{X}$-ray diffraction analysis of all the specimens less than $\mathrm{x}=15$ mol\% indicated orthorhombic phase. Thereafter, the specimens showed orthorhombic phase near to pseudo-cubic. Sinterablity of all the specimens was improved due to secondary products such as KCT and $\mathrm{KCN}$. The ceramics with $\mathrm{x}=5 \mathrm{~mol} \%$ showed the optimum velues of pizoelectric constant $\left(\mathrm{d}_{33}\right)=150$ $\mathrm{pC} / \mathrm{N}$, electromechanical coupling factor $(\mathrm{kp})=0.45$, electromechanical quality factor $(\mathrm{Qm})=418.9$ and dielectric constant $\left(\varepsilon_{\mathrm{r}}\right)=567$. Accordingly, These results indicate that the composition ceramics is a promising candidate for lead-free material.
\end{abstract}

Keywords: Non-stoichiometric, Piezoelctric, Ta, NKN

\section{1. 서 론}

일반적으로, 압전세라믹스는 $\mathrm{Pb}(\mathrm{Zr}, \mathrm{Ti}) \mathrm{O}_{3}(\mathrm{PZT})$ 와 같은 preovskite 구조를 갖는 조성이 우수한 압전 특 성과 높은 큐리온도 등으로 인하여 압전 변압기,초음 파센서, 액츄에이터, 레조네이터 및 필터 등에서 널 리 사용되어지고 있다.

하지만 $\mathrm{PZT}$ 계 세라믹스와 같은 $\mathrm{PbO}$ 가 포함되어 있는 물질은 $1,000^{\circ} \mathrm{C}$ 부근에서 급격한 휘발에 따른 손실과 그에 따른 조성의 변화로 인하여 압전특성의

a. Corresponding author; juhyun57@semyung.ac.kr
감소와 인체에 치명적인 중독 문제를 야기시키며, 환 경오염에 관한 문제로 인하여 사용이 규제되고 있는 추세이다. 그 결과 $\mathrm{Pb}$ 가 포함되지 않은 무연 압전 세 라믹스의 개발에 많은 연구가 이루어지고 있으며 2004년에 Saito 등에 의해 개발된 NKN 압전 세라믹 스 조성이 우수한 압전 특성과 큐리 온도 $\left(430^{\circ} \mathrm{C}\right)$ 로 인하여 많은 주목을 받고 있다 [1]. 하지만, 순수한 $\mathrm{NKN}$ 세라믹스는 일반적인 보통 소결방법을 통해서 는 낮은 밀도 등으로 인하여 압전 디바이스로 적용하 기에는 큰 어려움을 겪고 있다. 이에 따른 해결책으 로 $\mathrm{Li}, \mathrm{Bi}, \mathrm{Sb}, \mathrm{Ce}, \mathrm{Ta} \mathrm{KCT}, \mathrm{KCN}$ [2-8] 등과 같은 
다른 첨가물을 치환 혹은 첨가하는 방식으로 특성을 개선시키는 방법이 주로 논의되고 있으며, 이 이외에 조성의 불균형을 이루는 비화학량론적 조성 또한 소 개 되었다. 화학량론에서 벗어난 조성을 비화학량론 적 조성이라 부르며, 비화학량론적 조성은 그레인 모 양, 결정학적 구조의 결함, 전기 전도성과 같은 물리 적 특성에 영향을 미친다는 것이 발견되어졌다. 비화 학량론적 조성은 세라믹의 미세구조와 소결성 등에 원인을 줄 수 있기 때문에 비화학량론적 조성 세라믹 에 관한 연구는 우수한 압전특성을 갖는 $\mathrm{Pb}-\mathrm{free}$ 압 전재료를 개발하기 위하여 필요하다.

$\left(\mathrm{K}_{\mathrm{x}} \mathrm{Na}_{1-\mathrm{x}}\right)\left(\mathrm{Nb}_{\mathrm{y}} \mathrm{Sb}_{1-\mathrm{y}}\right) \mathrm{O}_{3}$ 세라믹스는 $\mathrm{ABO}_{3}$ 페로브스 카이트 구조를 가지고 있다. 만일 $\left(\mathrm{K}_{\mathrm{x}} \mathrm{Na}_{1-\mathrm{x}}\right)$ 의 $\mathrm{A}$-site $\mathrm{mol}$ 퍼센트가 $\left(\mathrm{Nb}_{\mathrm{y}} \mathrm{Sb}_{1-\mathrm{y}}\right)$ 의 $\mathrm{B}$-site $\mathrm{mol}$ 퍼센트보다 작다면 비화학량론적 조성을 만들 수 있다 $[9,10]$. 또 한, 비화학량론적 조성일 경우 $\mathrm{K}_{2} \mathrm{CO}_{3}, \mathrm{Na}_{2} \mathrm{CO}_{3}, \mathrm{Nb}_{2} \mathrm{O}_{5}$, $\mathrm{Sb}_{2} \mathrm{O}_{5}, \mathrm{CuO} \mathrm{Ta}_{2} \mathrm{O}_{5}$ 가 혼합된 경우 하소과정에서 서로 반응하여 $\mathrm{K}_{\mathrm{a}} \mathrm{Cu}_{\mathrm{b}} \mathrm{Nb}_{\mathrm{c}} \mathrm{O}_{\mathrm{d}}$ [6], $\mathrm{K}_{\mathrm{a}} \mathrm{Cu}_{\mathrm{b}} \mathrm{Ta}_{\mathrm{c}} \mathrm{O}_{\mathrm{d}}$ [7]와 같은 2 차 생성물을 생성한다. 이 이차 생성물은 소결조제로 서 작용하여 소결온도를 낮추고, 유전 및 압전특성을 향상시킬 수 있다 [9].

본 실험에서는 우수한 압전특성을 갖는 비화학량론적 조성의 압전 세라믹스를 개발하기 위하여 $\left[\left(\mathrm{K}_{0.5 \mathrm{Na}} \mathrm{Na}_{0.5}\right)\right.$ $\left.{ }_{0.97}\right]\left(\mathrm{Nb}_{0.96-\mathrm{x}} \mathrm{Ta}_{\mathrm{x}} \mathrm{Sb}_{0.04}\right) \mathrm{O}_{3}+0.008 \mathrm{CuO}+0.2 \mathrm{wt} \% \mathrm{Ag}_{2} \mathrm{O}$ $+0.2 \mathrm{wt} \% \mathrm{CeO}_{2}$ 의조성에 $\mathrm{Ta}$ 의 치환량의 변화를 주어 그에 따른 압전 및 유전 특성을 조사하였다.

\section{2. 실험 방법}

본 실험은 다음과 같은 조성식을 이용하여 일반적 인 산화물 혼합법에 의해 시편을 제조하였다.

$\left[\left(\mathrm{K}_{0.5} \mathrm{Na} \mathrm{Na}_{0.5}\right)_{0.97}\right]\left(\mathrm{Nb}_{0.96-\mathrm{X}} \mathrm{Ta}_{\mathrm{x}} \mathrm{Sb}_{0.04}\right) \mathrm{O}_{3}+0.008 \mathrm{CuO}$ $+0.2 \mathrm{wt} \% \mathrm{Ag}_{2} \mathrm{O}+0.2 \mathrm{wt} \% \mathrm{CeO}_{2} \quad$ [9]

$$
(\mathrm{X}=0,5,10,15,20,25 \mathrm{~mol} \%)
$$

$\mathrm{Ag}_{2} \mathrm{O}$ 를 제외한 원료는 조성식에 따라 $99 \%$ 이상의 순도를 가지는 시료를 $10^{-4} \mathrm{~g}$ 까지 측량하였고 아세톤 을 분산매로 하여 $3 \Phi$ zirconia ball을 사용하여 24시 간 동안 혼합, 분쇄하였다. 혼합 분쇄된 시료는 $900^{\circ} \mathrm{C}$ 6시간 동안 하소하였다.

하소한 후 첨가제 $0.2 \mathrm{wt} \% \mathrm{Ag}_{2} \mathrm{O}$ 를 2차 혼합 분쇄
하였다.

건조된 시료에 PVA (0.5 wt\% 수용액) $5 \mathrm{wt} \%$ 를 첨가하고 $21 \Phi$ 성형 틀에 $15 \mathrm{MPa}$ 의 힘을 가하여 성 형하였다. 성형된 시편은 $600^{\circ} \mathrm{C}$ 에서 3 시간 동안 $\mathrm{PVA}$ 를 태워버린 후, 승하강 온도 구배를 $5{ }^{\circ} \mathrm{C} / \mathrm{min}$ 로 하여 $1.100^{\circ} \mathrm{C}$ 에서 5 시간 소결하였다. 소결된 시편을 $1 \mathrm{~mm}$ 의 두께로 연마하고 $\mathrm{Ag}$ 전극을 스크린 프린트 법으로 도포한 뒤, $600^{\circ} \mathrm{C}$ 에서 10 분 간 열처리하였고 $30^{\circ} \mathrm{C}$ 실 리콘 오일 속에서 $3 \mathrm{kV} / \mathrm{mm}$ 의 직류 전계를 30 분 간 인가하여 분극하였다.

분극된 시편을 24 시간 경과 후 impedence analyzer (Agilent 4294)를 이용하여 주파수 및 impedence 특성을 측정하였고, LCR meter (ANDO $\mathrm{AG} 4304)$ 를 이용하여 $1 \mathrm{KHz}$ 의 주파수로 유전 특성을 측정하였다. 시편의 압전 및 유전 특성은 $\mathrm{IEEE}$ 에서 규정에 따라 공진 반공진 법을 이용하여 계산하였으 며 [11], 시편의 미세 구조 및 결정 구조는 각각 SEM (scanning electron microscope)과 XRD (X-ray diffraction)를 이용하여 관찰하였다.

\section{3. 결과 및 고찰}

그림 $1(\mathrm{a})$ 는 $\mathrm{Ta} \mathrm{mol} \%$ 변화에 따른 $\mathrm{XRD}$ 회절 패 턴이다. $\mathrm{XRD}$ 회절 분석 결과 전형적인 perovskite 구 조를 보이고 있다.

그림 $1(\mathrm{~b})$ 는 $43^{\circ}$ 에서 $48^{\circ}$ 까지 확대된 그림이다. 그 림에서 알 수 있듯이 $\mathrm{Ta}$ 가 $0 \mathrm{~mol} \%$ 부터 $15 \mathrm{~mol} \%$ 까 지 모두 orthorhombic 상인 것을 확인할 수 있으나 이 이후 (202), (020) 사이 점차 단일 피크로 됨에 다 라 상온에서 orthorhombic 상이 약하여 pseudo-cubic 상에 가깝다고 사료된다. 이 이유는 $\mathrm{Ta}$ 의 과잉 치환 에 따른 상의 변화로 해석된다 [12]. 또한, $35^{\circ}$ 부근 에 이차상이 발견되기는 하였으나 무시할 수 있을 정 도로 작기 때문에 시편의 특성에 영향을 미치지 못하 는 것으로 보인다 [13].

그림 2는 $\mathrm{Ta}$ 치환량에 따른 $\mathrm{SEM}$ 이미지를 나타내 고 있다. $\mathrm{Ta}$ 치환량에 따라 입경은 $3.36 \mu \mathrm{m}, 3.2 \mu \mathrm{m}$, $2.98 \mu \mathrm{m}, 2.68 \mu \mathrm{m}, 2.22 \mu \mathrm{m}, 1.45 \mu \mathrm{m}$ 로 각각 조사되 었다. 이를 통해 입경은 $\mathrm{Ta}$ 치환량에 따라 서서히 감 소하는 경향을 확인할 수 있다. 원인으로 비화학양론 조성에서 하소과정에서 생성된 이차 생성물 $\mathrm{K}_{\mathrm{a}} \mathrm{Cu}_{\mathrm{b}} \mathrm{Nb}_{\mathrm{c}} \mathrm{O}_{\mathrm{d}}$ (이하 $\mathrm{KCN}$ ), $\mathrm{K}_{\mathrm{a}} \mathrm{Cu}_{\mathrm{b}} \mathrm{Ta}_{\mathrm{c}} \mathrm{O}_{\mathrm{d}}$ (이하 $\mathrm{KCT}$ ) 등이 소결조제로써 작용하여 소결온도에 영향을 주 

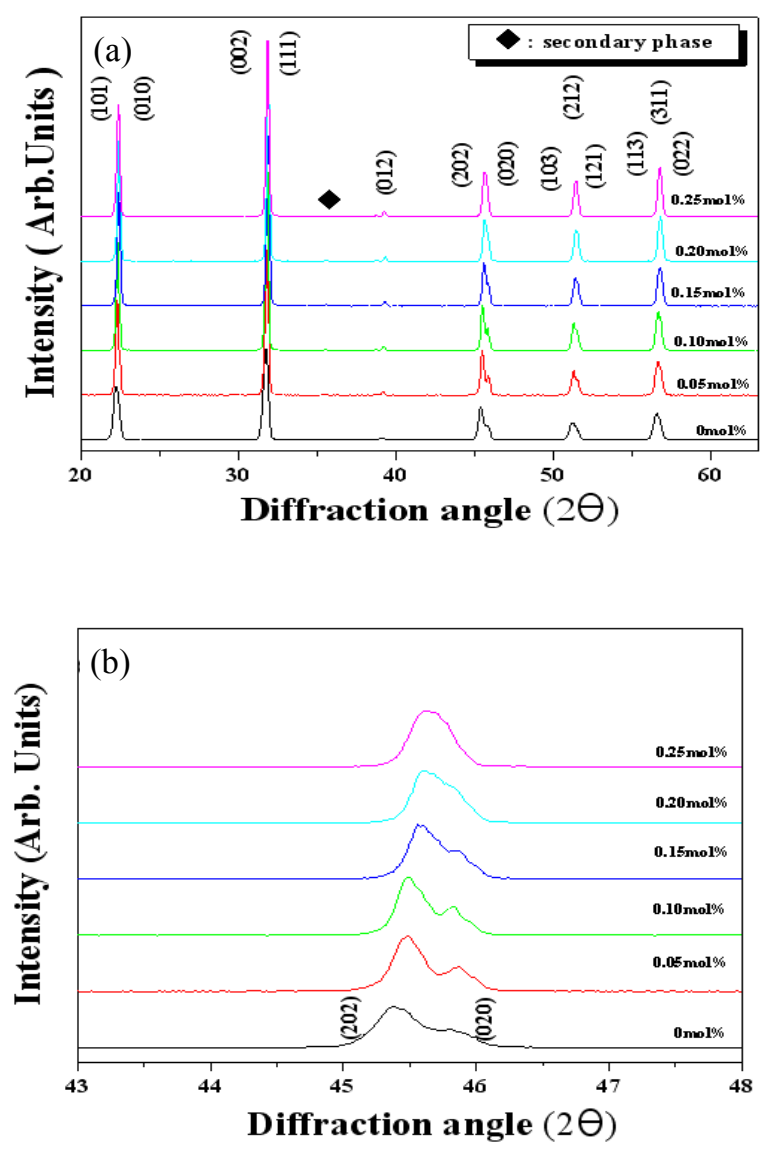

Fig. 1. X-ray diffraction pattern as a function of $\mathrm{Ta}$ concentration in the range $2 \Theta\left(\right.$ (a) $20^{\circ} \sim 60^{\circ}$, (b) $43^{\circ} \sim$ $48^{\circ}$ ).

어 grain들의 성장을 억제하여 치밀화된 것이라 사 료된다.

그림 3은 $\mathrm{Ta}$ 치환량에 따른 밀도를 나타내고 있다. 밀도는 $\mathrm{Ta}$ 치환량에 따라 $4.49 \mathrm{~g} / \mathrm{cm}^{3}$ 로부터 서서히 증가하여 $4.95 \mathrm{~g} / \mathrm{cm}^{3}$ 의 값에 도달하였다. 이와 같이 밀도가 증가한 것은 역시, 하소과정에서 생성된 이 차 생성물 $\mathrm{KCN}, \mathrm{KCT}$ 등이 액상으로 작용하여 소 결성을 향상시킨 것으로 생각된다.

그림 4 는 $\mathrm{Ta}$ 치환에 따른 전기기계 결합계수 $\left(\mathrm{k}_{\mathrm{p}}\right)$ 이다. $\mathrm{Ta}$ 치환량의 증가에 따라 $\mathrm{k}_{\mathrm{p}}$ 는 증가하여 5 $\mathrm{mol} \% \mathrm{Ta}$ 에서 최고의 값 0.457 을 보이고 이후 감소하 였다. 이는 소결 조제로써 형성되어, 작용한 $\mathrm{KCT}$, $\mathrm{KCN}$ 이 소결성을 개선시켜 전기기계결합계수가 증가 되고, 과잉 치환 시에는 그레인 경계에 편석량이 증 가하여 하락한 것으로 생각된다.
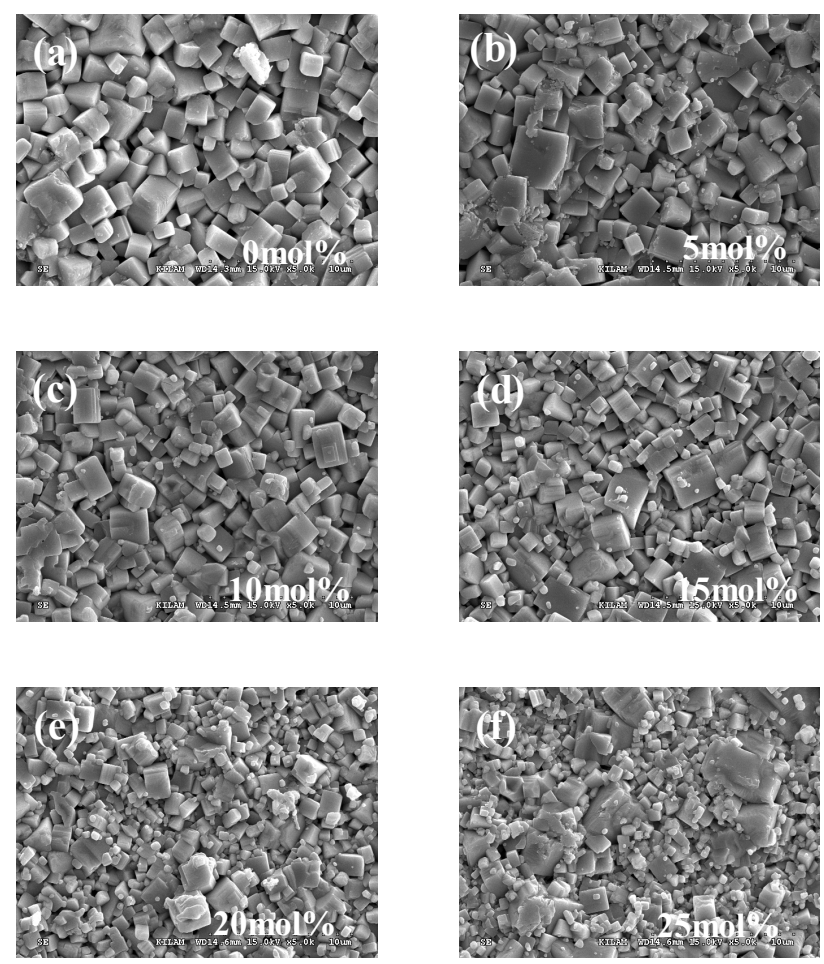

Fig. 2. Microstructure as a function of Ta concentration. (a) 0 mol\% $\%$ a, (b) 5 mol\% $\%$ a, (c) 10 mol\% $\mathrm{Ta}$, (d) 15 mol\% Ta, (e) 20 mol\% Ta, and (f) 25 mol\% $\mathrm{Ta}$.

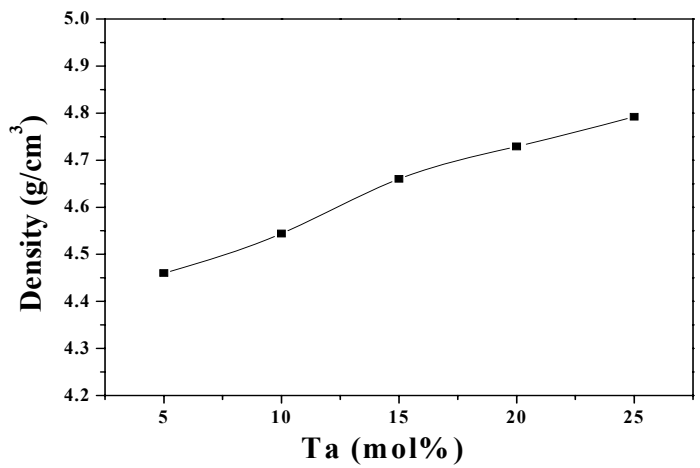

Fig. 3. Sintered density as a function of Ta substitution level.

그림 5는 $\mathrm{Ta}$ 치환량에 따른 기계적 품질계수이다. 보 편적인 경우 전기기계결합계수 $\left(\mathrm{k}_{\mathrm{p}}\right)$ 와 반비례하는 경향 을 보인다. 그러나, $\mathrm{k}_{\mathrm{p}}$ 와 같이 증가 후 감소하는 경향을 보이고 있다. 이 또한 소량 $\mathrm{Ta}$ 치환 시 소결 조제로써 형성되어 작용한 $\mathrm{KCT}, \mathrm{KCN}$ 이 소결성을 개선시킨 결과 로 사료되며, $10 \mathrm{~mol} \%$ 에서 최고의 값 654 를 나타냈다. 


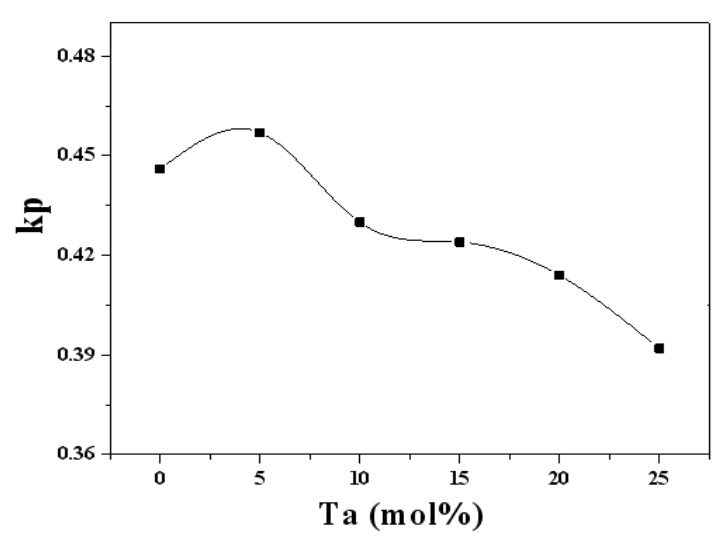

Fig. 4. Electromechanical coupling factor $\left(k_{p}\right)$ with the amount of Ta concentration.

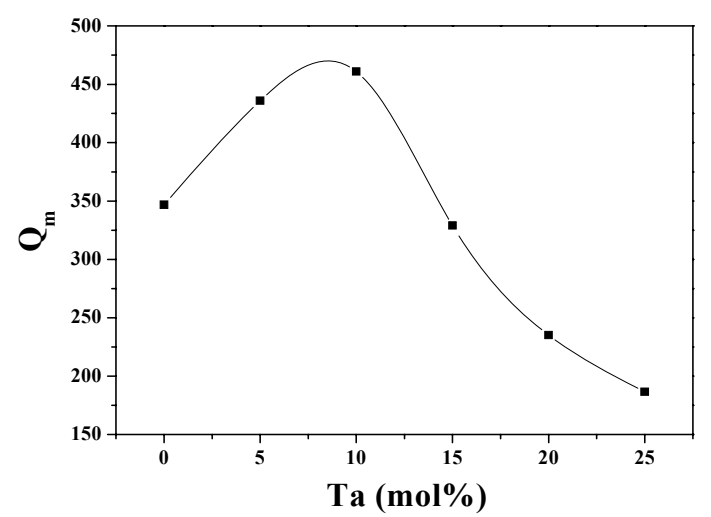

Fig. 5. Mechanical quality factor $\left(\mathrm{Q}_{\mathrm{m}}\right)$ as a function of Ta concentration.

그림 6 은 $\mathrm{Ta}$ 치환량에 따른 유전상수 $\left(\varepsilon_{\mathrm{r}}\right)$ 이다. $\mathrm{Ta}$ 치환량의 증가에 따라 유전상수 $\left(\varepsilon_{\mathrm{r}}\right)$ 는 $0 \mathrm{~mol} \% \mathrm{Ta}$ 의 값 486 에서 시작하여 $25 \mathrm{~mol} \% \mathrm{Ta}$ 의 값 1,289 까지 점차 증가한다. 이러한 결과는 소결 조제로써 형성되 어 작용한 $\mathrm{KCT}, \mathrm{KCN}$ 효과 보다는 $\mathrm{Ta}$ 치환의 증가에 따른 1 차 상전이온도 $\left(\mathrm{T}_{\mathrm{ot}^{-t}}\right)$ 가 점차 상온 쪽으로 이동 해 감에 따라 상온에서 유전상수를 증가시킨 것으로 생각된다.

그림 7 은 $\mathrm{Ta}$ 치환량에 따른 압전상수 $\left(\mathrm{d}_{33}\right)$ 이다. $\mathrm{Ta}$ 치환량의 증가에 따라 압전상수 $\left(\mathrm{d}_{33}\right)$ 는 유전상수 와 마찬가지로 $0 \mathrm{~mol} \% \mathrm{Ta}$ 의 값 $135 \mathrm{pC} / \mathrm{N}$ 에서 시작 하여 $25 \mathrm{~mol} \% \mathrm{Ta}$ 의 값 $186 \mathrm{pC} / \mathrm{N}$ 까지 점차 증가하였 다. 이것은 유전상수의 증가에 따라 증가한 것으로 생각된다.

그림 8은 $\mathrm{Ta}$ 치환량에 따른 유전상수 온도 의존성을

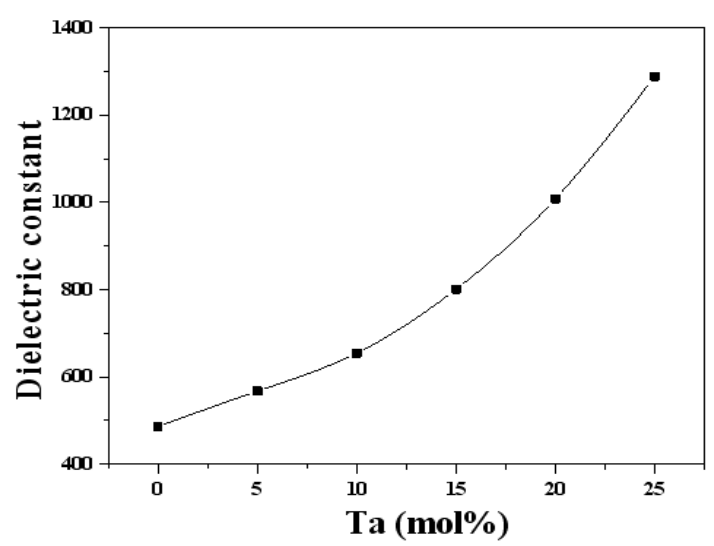

Fig. 6. Dielectric $\operatorname{constant}\left(\varepsilon_{\mathrm{r}}\right)$ as a function of Ta concentration.

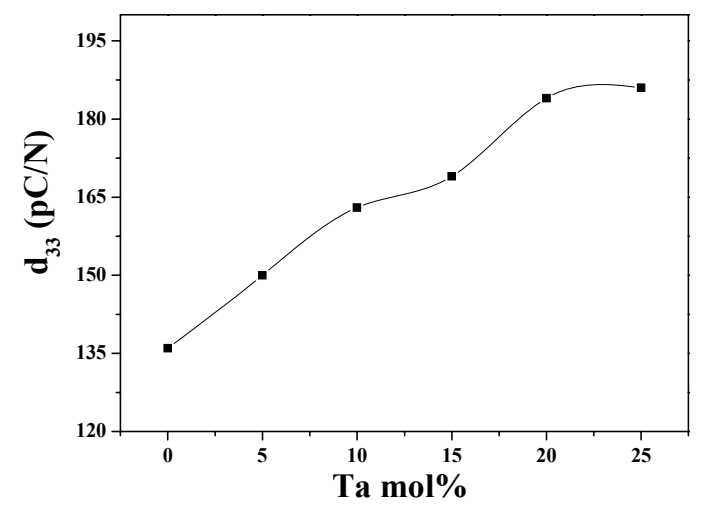

Fig. 7. Piezoelectric constant $\left(\mathrm{d}_{33}\right)$ as a function of $\mathrm{Ta}$ concentration.

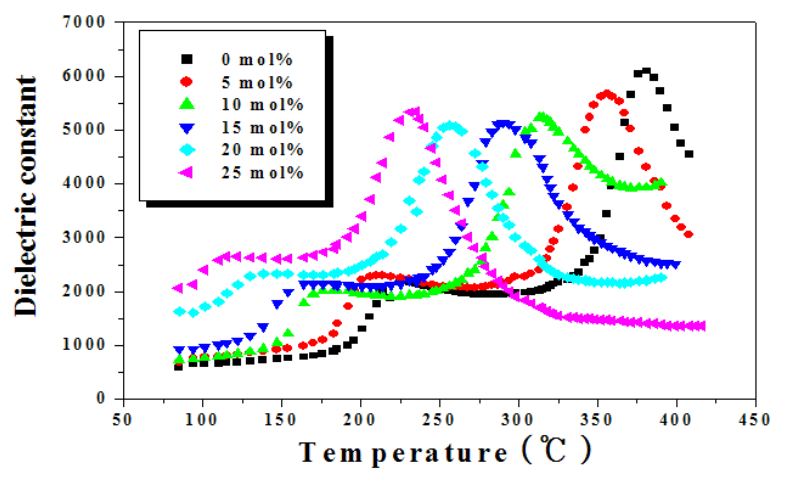

Fig. 8. Dieletric constant as a function of $\mathrm{Ta}$ concentration .

나타내고 있다. 치환량의 증가에 따라서 orthorhombic 상에서 tetragonal 상으로 일차상전이 온도 $\left(\mathrm{T}_{0-\mathrm{t}}\right)$ 가 낮은 온도 범위 쪽으로 이동하는 것을 확인할 수 있고, 
Table 1. Physical characteristics of the sample with the amount of Ta substitution.

\begin{tabular}{ccccccccc}
\hline $\begin{array}{c}\text { Sintering } \\
\text { Temp. }\left[{ }^{\circ} \mathrm{C}\right]\end{array}$ & $\mathrm{mol} \%$ & $\begin{array}{c}\text { Density } \\
{\left[\mathrm{g} / \mathrm{cm}^{3}\right]}\end{array}$ & $\mathrm{k}_{\mathrm{p}}$ & $\mathrm{Q}_{\mathrm{m}}$ & $\begin{array}{c}\mathrm{d}_{33} \\
{[\mathrm{pC} / \mathrm{N}]}\end{array}$ & $\begin{array}{c}\text { Dielectric } \\
\text { constant }\end{array}$ & $\mathrm{To-t}$ & $\mathrm{Tc}$ \\
\hline & 0 & 4.495 & 0.446 & 346 & 135 & 486 & 217 & 372 \\
& 5 & 4.578 & 0.457 & 436 & 150 & 567 & 198 & 348 \\
& 10 & 4.683 & 0.430 & 460 & 163 & 654 & 183 & 315 \\
1100 & 15 & 4.804 & 0.424 & 328 & 169 & 801 & 164 & 298 \\
& 20 & 4.883 & 0.414 & 235 & 183 & 1008 & 147 & 256 \\
& 25 & 4.953 & 0.392 & 136 & 186 & 1289 & 130 & 235 \\
\hline
\end{tabular}

tetragonal 상에서 cubic 상으로 변하는 curie 온도 $\left(\mathrm{T}_{\mathrm{c}}\right)$ 또한 마찬가지 현상을 보이고 있다. $\mathrm{T}_{\mathrm{o}-\mathrm{t}}$ 는 $217^{\circ}$ 에서 $130^{\circ} \mathrm{T}_{\mathrm{c}}$ 는 $372^{\circ}$ 에서 $235^{\circ}$ 로 이동하였다.

\section{4. 결 론}

본 연구에서는 $\quad\left[\left(\mathrm{K}_{0.5} \mathrm{Na}_{0.5}\right)_{0.97}\right]\left(\mathrm{Nb}_{0.96-\mathrm{X}} \mathrm{Ta}_{\mathrm{x}} \mathrm{Sb}_{0.04}\right)$ $\mathrm{O}_{3}+0.008 \mathrm{CuO}+0.2 \mathrm{wt} \% \mathrm{Ag}_{2} \mathrm{O}+0.2 \mathrm{wt} \% \mathrm{CeO}_{2}$ 의 조성에 $\mathrm{Ta}$ 의 치환량의 변화를 주어 그에 따른 압전 및 유전 특성에 대하여 조사한 결과 다음과 같은 결 론을 얻었다.

1. $\mathrm{XRD}$ Ta $0 \mathrm{~mol} \%$ 부터 $15 \mathrm{~mol} \%$ 까지 모두 orthorhombic상인 것을 확인할 수 있으나 이 이후 (202), (020) 사이 점차 단일 피크로 됨에 따라 상온 에서 orthorhombic 상이 약하여 pseudo-cubic에 가깝 다고 사료된다.

2. $\mathrm{Ta}$ 치환량의 증가는 grain의 성장을 억제하고 치밀화시켜 고밀도의 세라믹스를 얻을 수 있었다.

3. $\mathrm{Ta}$ 의 치환량의 증가에 따라 $\mathrm{To}^{-\mathrm{t}}$ 와 $\mathrm{Tc}$ 모두 낮 은 온도 쪽으로 이동하였다.
4. $\mathrm{Ta}$ 가 $5 \mathrm{~mol} \%$ 치환된 조성에서 압전상수 $\left(\mathrm{d}_{33}\right)=$ $150 \mathrm{pC} / \mathrm{N}$, 전기기계결합 계수 $(\mathrm{kp})=0.45$, 기계적 품 질계수 $(\mathrm{Qm})=418.9$, 유전상수 $\left(\varepsilon_{\mathrm{r}}\right)=567$ 의 최적의 특 성을 보였다.

\section{REFERENCES}

[1] M. Tackafumi, T. Norihito, I. Mutstuo, H. Tobias, and M. Takeshi, Mater. Lett., 64, 125 (2010).

[2] Y. Oh, J. Noh, J. Yoo, J. Kang, and L. Hwang, Transactuactions on Ultrasonics, Ferroelectrics, and Frequency Control, 58, 1860 (2011).

[3] Y. Guo, K. Kakimoto, and H. Ohsato, Appl. Phys. Lett., 85, 4121 (2004).

[4] M. Matsubara, K. Kikuta, and S. Hirano, J. Appl. Phys., 97, 114105 (2005).

[5] Y. Guo, K. Kakimoto, and H. Ohsato, Mater. Lett., 59, 241 (2005).

[6] M. Matsubara, T. Yamaguchi, W. Sakamoto, K. Kikuta, T. Yogo, and S. J. Hirano, J. Am. Ceram. Soc., 88, 1190 (2005).

[7] S. J. Zhang, R. Xia, T. R. Shrout, G. Z. Zang, and J. F. Wang, J. Appl. Phys., 100, 104108 (2006).

[8] Y. Lee, J. Yoo, K. Lee, I. Kim, J. Song, and Y. W. Park, J. Alloys and Comp., 506, 872 (2010).

[9] F. Rubio-Marcos, P. Marchet, T. Merle-Mejean, and J. F. Fernandez, Mater. Chem. Phys., 123, 91 (2010).

[10] S. H. Moon, S. H. Han, H. W. Kang, H. G. Lee, K. W. Chae, J. S. Kim, and C. I. Cheon, Ceramics International, 38S, 343 (2012).

[11] IEEE Standards on Piezoelectricity, The Institute of Electrical and Electronics Engineers Inc., IEEE Standard, 176 (1978).

[12] C. Yun, Y. Zupei, and W. Lingling, J. Am. Ceram. Soc., 90, 1656 (2007).

[13] D. Lin, K. W. Kwok, and H. L. W. Chan, Appl. Phys., A91, 167 (2008). 